\title{
The Study of Collaborative Innovation of IMIS Talent Cultivation in the Independence
}

College

Chen senling ${ }^{1}$,Li xiaofei ${ }^{2}$, Jin jian $^{3}$

1 Guangdong Teachers College of Foreign Language and Arts,Guangzhou, 510640

2 Zhujiang College, South China Agricultural University,Guangzhou,510900

3 The IT Department of Guangzhou Railway Group Corporation, Guangzhou,510010

Abstract: Viewing the collaborative innovation as the guiding ideology, this paper is based on the Current status of Independent Colleges of Guangdong Province, and proposed three training directions of Information management and information systems(short for IMIS) in order to strengthen the core construction of this major. Also, we make great effort to improve the teaching quality and training quality by amending the educational program, setting the course system, strengthening the construction of teachers and changing the class mode. We made an experiment Zhujiang College ,South China Agricultural University and took active teaching reform in order to explore a suitable way for the independent Colleges and an actively promotion for collaborative innovation talent Cultivation.

Keyword: information management and information system; Collaborative Innovation; Talent Cultivation

\section{Introduction}

On April 24 2011, The Chairman Hu Jintao proposed that the "collaborative innovation" on the strategic height of building an innovative country when celebrating the 100th anniversary of Tsinghua University. He emphasized that colleges and universities should enhance the original innovation and the integrated innovation, introduce the ability of digestion and absorption re-innovation. Meanwhile they also should actively promote the collaborative innovation ${ }^{[1]}$. As we know, the scientific research institutes, industry area, local governments and some related organizations are collaborators with higher education in talent cultivation. How to make these collaborators focus on this common goal, intrinsic motivation? How to make them communication with each other directly? How to rely on modern information technology and build a resource platform for multi-faceted communication and diverse cooperation? How to take advantage of collaborative innovation to promote the talent cultivation of higher education, especially independent Colleges? All the answers can be related to the "broad" overage of Higher Education and also the "special" mechanism of talent cultivation.

In current talent cultivation system, social organization or collaborators, including enterprises, institutions, social groups or individuals and others were allowed to attach to higher schools and organize the undergraduate level education. That is so called independent colleges. They became more and more important for our higher education. Their talent cultivation strategic meets the needs of local economic development and trains their student to learn certain theory and adapt the social quickly and become to be a vibrant, high-quality talent ${ }^{[2]}$. This article is a study on independent colleges in Guangdong Province, and also a practice on the major of Information Management and Information(referred to as IMIS later) of Zhujiang College of South China 
Agricultural University. We intended to explore a new way for IMIS in these independent colleges to apply the collaborative innovation in talent cultivation of IMIS, finally enhance the connotation construction and step up the whole strength of our teaching and improve the training quality

\section{Current Stations}

It was reported ${ }^{[3]}$ that there are 17 independent colleges in Guangdong Province, such as Zhuhai College of Jilin University, Southern College of Zhongshan University, Zhujiang College of South China Agricultural University, Pearl River College (referred to as Zhujiang College later). All of them operated at their own degree in 2002, and 10 of them had the IMIS major and awarding the management Science bachelor's degree. For example, Zhujiang College had received its undergraduates of IMIS since 2006. The students of this major is up to 242 now, and the number of the graduated is 311. Most of them were employed in various enterprises in Guangdong province such as banks, schools, state-owned enterprises, local governments. Unfortunately some outstanding problems, which were mainly reflected in the following aspects, were found in the school running and major construction of most independent colleges.

1) At present, most of the independent colleges in Guangdong province which were funded by private companies or person took the management of private mechanisms. At the same time, the attached schools only provided their brand impact and management support, excluding the financial support.

2) Independent Colleges had limited to the relevant provisions such as major construction, professional title assessment, and treatment of teachers. The advantages of autonomy had not been fully carried forward, even the major curriculum is identical with the attached school lack of their own characteristics and discrimination.

3) Due to the limitation of teacher resources and the practice, the IMIS in great majority of independent colleges had covered a wide range field and then get blurred in the course boundaries. As a result, in this professional construction of IMIS, we could found out a lot of problem, such as different core curriculums, inconsistent training objectives, inconspicuous content about management science and a poor combination of the theoretical knowledge with practice skills.

To solve these problems, we took the Zhujiang College as our study case, summarized our research experience in multi-partite collaboration with the IT department of Guangzhou Railway Group and library, found out the combination way between the theoretical knowledge with practical skills, carried forward the purpose of collaborative cultivation.

\section{Major measures}

\subsection{Building up the guiding ideology}

"Collaborative Innovation" means that the resources and elements of innovation should be effectively integrated by breaking through the barriers between the collaborators and fully releasing the innovative elements such as "talent, capital, information, and technology, and consequently can be leaded into depth cooperation ${ }^{[4]}$. In real terms from the professional point of view, the IMIS major is designed to enable students to develop an inter-disciplinary talent to meet the need of the socialist market economy with multi-disciplinary professional knowledge of information technology, modern management, economy, network technology, enterprise business and so on. In other words, it is composite, application-oriented and innovative 
entrepreneurial. This professional training purpose determines that students should make a professional integration of theoretical knowledge of management disciplines, computer science, system disciplines, teacher should be those professors who had good study in economic management and computer science, and classes should introduce those actual projects support about computer software development, computer applications and so on. So, we can say it possible to apply the collaborative innovation mechanism for its professional construction.

3.2 Revising the training program of talents

Personnel training program is a fundamental for professional construction. When revising the professional personnel training, it should not only take full account of the relevant regulations and policies and the suitable professional curriculum, but also should fully integrate with the actual educational station and the employment needs and strengthen the practice innovative ability.

According to the Curriculum System 2011 of Information Systems of China [4], which is developed by the Steering Committee of the Ministry of Education Subject Teaching ,as well as the research of Professor Hou Yue Fang, we refer to the same major's curriculum system of the influent institutions such as Guangxi University, Fujian Engineering College, Sun Yat-sen University, Wuhan University and other institutions, combined with the employment situation and the needs of the industry in the zhujiang delta area, as well as the characteristics of independent Colleges factors, we believe that in the process of optimizing personnel training program, talent cultivation of IMIS should fully considered about the professional evolution, that is, we should not only focus on information system development and design capabilities, but also reflect the overall quality of the management of information resources, and then combine with the local employment needs, we can propose three training directions on this special major: information resources development and management, information systems development and management, IT and marketing service and their corresponding teaching plan, so that we can make full use of the advantage of inter-disciplinary talent.

\section{3 strengthing the construction of teacher}

Inadequate teacher is one of the greatest difficulties of Independent Colleges. In order to support the personnel training system reasonably and strengthen the collaborative cultivation, Three measures can be taken to improve teacher overall level: First of all, because of the multi-disciplinary field of the IMIS major, it is necessary to integrate the teacher resource in the college units, such as the department of management, the department of accounting, the library and others related. They can teach relevant courses of management science and principles of accounting and information retriever. Another collaborative way is building the library as in-campus teaching practice base, which can not only support the teaching plan but also provide the real internship environment; Second, Independent Colleges can fully rely on their attached institutions, and actively introduce senior engineer of collaborative enterprises, so as to enrich the existing teachers and improve the reserve forces; Last but not the least, It goes without saying that to forge iron, one must be strong. The college should especially encourage their full-time teachers take advantage of the winter and summer vacation time and go out of school to learn at least in one or several areas with the latest technology standards. When they 
came back they can extend the class and improve the teaching level.

\section{4 changing the teaching mode}

The current higher education is not got rid of the "teachers-centered", "classroom-centered ", "textbooks-centered" closed classroom teaching mode. Guiding in the collaborative innovation advocate, school-enterprise cooperation can be vigorously carried out by collaborating on projects as main form, and the combination of education platform can be built to combine the classroom teaching and extra-curricular activities, also with school teaching and campus practice. So that classroom teaching mode can extend to the extracurricular and even off-campus, then enable curricular and extracurricular classroom combination of inside and outside the school, thereby improve the quality of education and teaching, apply the training innovative talents, and provide quality service for the sound eco-social development. The teaching reform ${ }^{[5]}$ in the Management Information System, the professional core lesson of IMIS of Zhujiang College indicated that it is useful for strengthen the teaching effectiveness that introducing some engineers of IT department of Guangzhou Railway Group Corporation in the class. Those engineers can pass their experience to student and give professional advice when displaying student work, which feed backed a lot improvement of students' practical skills and teamwork ability.

\section{CONCLUSIONS}

The independent college can supply both the amount of Undergraduate scale and qualitative type of talent. Lot of social forces participate in this kind of higher education such as the local government, attached school, corporate investors and others. So it has the natural advantage that can transform the social resources to strengthen collaborative innovation.
The information management and information System discussed in this article had set up in 10 independent colleges in Guangdong Province. That is to say it is not only universal in Guangdong Province but also adaptive in the local economic development. We believe that the form of collaborative innovation does not stick to the text in the professional construction process. It is yet to be in the follow-up study of more scholars.

\section{ACKNOWLEDGEMENT}

Supported by Foundation of Guangdong Educational Committee, No. 2013LYM_0116.

\section{References}

[1] Ministry of Education of the People's Republic of China, The suggestions on the implementation of the innovation ability of higher education promotion planning by Ministry of finance and Ministry of education

[EB/OL], http://www.moe.edu.cn/publicfiles/business/htmlfiles /moe/A16_zcwj/201205/135177.html, May 4, 2012 [2] Zhu yanjun. Exploration and practice of interdisciplinary talents innovation cultivation mode in independent colleges [J]. China University Teaching.2012:(05):19-21

[3] Lai jingchao, Lei yu. Sueveys about 17 independent college of Guangdong Province: it is to early for The independent college to stand alone[N], Southern Daily, July 11, 2012 (A13)

[4] Hou yuefang. Investigation on the curriculum setting of the specialty of information management and information system [J], Journal of Medical Informatics,2012:(1):12-15

[5] Chen senling,Jin jian. The teaching reform in Management information system of practice class [J], Value engineering ,2011:(11):244

[6] Chen senling,Jin jian. The Practice of Information Management and Information Systems Professional Talents Cultivation in Independent Colleges [J], Value engineering ,2013:(17):222-223 